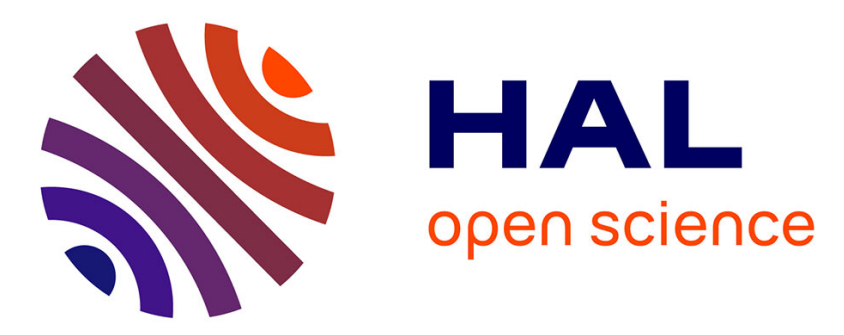

\title{
High strength-high conductivity fibre-reinforced copper alloys
}

C. Biselli, D. Morris

\section{To cite this version:}

C. Biselli, D. Morris. High strength-high conductivity fibre-reinforced copper alloys. Journal de Physique IV Proceedings, 1993, 03 (C7), pp.C7-1737-C7-1740. 10.1051/jp4:19937273 ～jpa-00251914

\section{HAL Id: jpa-00251914 https://hal.science/jpa-00251914}

Submitted on 1 Jan 1993

HAL is a multi-disciplinary open access archive for the deposit and dissemination of scientific research documents, whether they are published or not. The documents may come from teaching and research institutions in France or abroad, or from public or private research centers.
L'archive ouverte pluridisciplinaire HAL, est destinée au dépôt et à la diffusion de documents scientifiques de niveau recherche, publiés ou non, émanant des établissements d'enseignement et de recherche français ou étrangers, des laboratoires publics ou privés. 


\title{
High strength-high conductivity fibre-reinforced copper alloys
}

\author{
C. BISELLI and D.G. MORRIS*
}

Swissmetal Research Laboratories, Avenue de Bellevaux 51, 2000 Neuchâtel, Switzerland

* Institute of Structural Metallurgy, University of Neuchâtel, 2000 Neuchâtel, Switzerland

\begin{abstract}
High strength copper-based alloys reinforced with fibres of a bcc metal such as $\mathrm{Cr}, \mathrm{Nb}, \mathrm{Ta}$, produced by very high strain drawing of cast eutectic mixtures, have been studied for some time. Fine bcc fibres leading to high strength can be produced, but only for thin sheets or fine wires because the drawing strains necessary are so high $(>99.99 \%)$. Ultra-fine microstructures are produced here by using spray deposition techniques to give a finer starting microstructure than obtained by conventional casting, followed by high strain drawing to achieve high strengths in wires of reasonable diameters. The microstructures produced by these procedures are analysed by electron metallographic techniques and shown to be highly refined. Grain widths in the range $50-100 \mathrm{~nm}$ are produced with bcc metal fibres of thickness below $10 \mathrm{~nm}$. Once this nanometric level is attained the strength of the composite depends only on the scale of the component phases - that have no further internal structure - and strengthening mechanisms operating can be more easily determined. The fibres are seen to behave as an ideally-strong, dislocation-free material but which contribute only a small part of the composite strength. The most significant strengthening contributions arise from the refinement of the scale of the copper matrix, a refinement that is induced by the fibres stabilising grain boundaries.
\end{abstract}

\section{INTRODUCTION}

There has been a significant effort over the past decades to develop copper base alloys with better combinations of conductivity and strength. One of the areas investigated is that of the so-called "in situ" fibre composites where a second, ductile phase is transformed into fine, reinforcing fibres by a high strain working process such as wire drawing or sheet rolling. Such studies evolved from work on superconductor fabrication. From such studies, alloys such as $\mathrm{Cu}-20 \% \mathrm{Nb}$ or $\mathrm{Ta}$ have been reported $(1,2)$, where the cast structure containing bcc metal dendrites of thickness about $5-10 \mu \mathrm{m}$ is converted into a fibre-reinforced structure with metal fibres of thickness less than $100 \mathrm{~nm}$ by strains of the order of $99.995 \%$ reduction of area, and greater (such large strains are quoted as the natural logarithm of the strain - initial area/final area - which takes a value of 10 in the example given). As a result of such heavy working, the strength of the fibre composite becomes very high, in excess of $1000 \mathrm{MPa}$, and even in excess of $2000 \mathrm{MPa}$ for the strongest materials, at the same time maintaining a very good conductivity, of the order of $50-75 \%$ for the strong materials.

A major disadvantage of these materials is that the very high strains required ensure that the final material is obtained only in the form of thin wires or strips, typically less than $0.5 \mathrm{~mm}$ in dimension. For example, in the example quoted above, a cast ingot of $10 \mathrm{~cm}$ diameter is reduced to wire of diameter about $0.6 \mathrm{~mm}$, and even then the highest strengths are not achieved. This dimension is unfortunately too small for many of the applications, as liners in jet and rocket nozzles, as heat sinks in computer systems, as welding and erosion machine components, etc. 
The present study sets out to overcome this disadvantage by starting with the finer microstructures given by rapid solidification of the initial alloy. It is hoped that the same strengthening processes will operate on the fine fibres produced using a smaller imposed strain such that an initial largedimensioned billet will be converted into a product of useful dimension.

\section{EXPERIMENTAL DETAIIS}

The studies here used rapidly solidified powders of several $\mathrm{Cu}$-bcc metal alloys, which were consolidated by HIP and the billets obtained extruded commercially to round bar, which was subsequently drawn to wire on a laboratory drawing bench. The alloys studied were $\mathrm{Cu}-\mathrm{Cr}, \mathrm{Fe}$, and $\mathrm{Nb}$, containing about $5 \%$ by volume of the bec metal, and $\mathrm{Cu}-\mathrm{Cr}$ and $\mathrm{Fe}$, containing about $15 \%$ by volume of the bcc metal. The sharply increasing liquidus temperature of these alloy systems prohibited increasing further the bcc metal content while retaining reasonably accessible melting temperatures. Further studies are underway using spray forming to avoid the powder-atomisation and consolidation steps: preliminary results show that the same mterial behaviour will be obtained. Complete details of the processing conditions are described elsewhere (3).

Mechanical testing has been carried out both in tension and in compression, and microstructures examined by scanning and by transmission electron microscopy. Quantification of the metallographic features has been performed using a Quantimet 920 image analysing system.

\section{RESULTS}

The powders obtained were typically of sizes in the range $20-100 \mu \mathrm{m}$, and very coarse agglomerated or debris material was removed by seiving. The internal microstructure, illustrated in Fig. 1, showed a

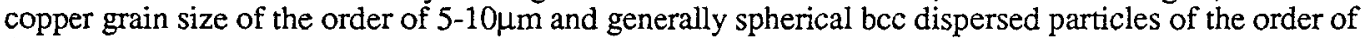
$1 \mu \mathrm{m}$ in dimension. The use of this rapid solidification procedure has led to the reduction in scale of the bcc metal by about one order of magnitude over that reported earlier on large scale casting.

During extrusion at about $750-800^{\circ} \mathrm{C}$, there was little tendency of the spherical dispersoids to elongate into fibres. This is probably because the soft copper matrix can deform easily around the harder bcc particles. During cold drawing, however, the bcc particles deform to become long fibres, as illustrated in Fig. 2. At the same time it may be seen that there was a notable volume fraction of spherical particles that did not deform, and remained nearly spherical. Analysis by EDS and by electron diffraction showed that some of these particles were oxides: it is probable that contamination, most probably by interstitial elements, of the bcc phase makes these sufficiently hard that they remain undeformable during drawing. The elongated particles actually adopt a ribbon morphology due to the requirements of compatibility of deformation between the matrix and the bcc phase and the deformation texture adopted by the bcc phase. In fact it has been shown that the copper takes up a mixed $<001\rangle$ and $<111>$ texture after deformation and the bcc phase a very strong $<110\rangle$ texture.

Examination of these wire composites by TEM, illustrated in Fig. 3, shows that extremely fine dimensions of copper grain and bcc metal fibre are achieved. In the present work, starting from finer dispersed bcc metal dimension, it is possible to achieve bcc fibre thicknesses of the order of $6-4 \mathrm{~nm}$ after drawing strains of "only" 6-8: that is after reductions of "only" $99.7 \%$ to $99.96 \%$. At the same time, the copper grain size is reduced to dimensions of the order of $110-75 \mathrm{~nm}$. Due to the peculiar form of the bec fibres, which are of course much wider than they are thick, these fibres tend to lie at the copper grain boundaries, and the composite is thus essentially composed of such fine copper grains, of square cross section with their grain boundaries decorated by bec metal phase.

The results of tensile testing are shown in Fig. 4 for all the materials tested to date. It is seen here that only the $\mathrm{Cu}-\mathrm{Fe}$ material shows a large strength increase as a result of drawing, and all the other composites show very limited strength increase after a drawing strain of about 2-4. The reason for this is two-fold: in the case of the dilute alloys (containing only $5 \%$ bec metal), there is insufficient fibre phase for notable strengthening; in the case of the $\mathrm{Cu}$-Cr alloy, presumably due to excessive interstitial contamination, the bcc phase does not form fibres. In all these cases, then, there is essentially only the work hardening of the copper matrix. 


\section{MODELLING OF STRENGTHENING}

Previous researchers have proposed two types of model to explain strengthening in these fibre reinforced materials. In the first model (4) it has been proposed that working introduces a high number of geometrically-necessary dislocations at the matrix-fibre interfaces. In general there has not been evidence of the large numbers of dislocations that would not be required; in the present case where both copper grains and iron fibres reach such fine dimensions that both tend to become dislocationfree - note that the iron fibres are in fact nanoscale objects and show no signs of containing dislocations - this dislocation substructure model seems to have no applicability. In the second model $(5,6)$, it is considered that the strength of the composite is the volume-weighted average of the strengths of each component phase, and each can be described by an Orowan-dislocation-bowing mechanism. The equation shown below has then been deduced $(5,6)$, to describe the strength of the material composed of volume fractions $f$ of each phase, with an intrinsic strength of $\sigma_{0}$ and dimension $t$ (the Taylor factor (M), a geometric constant (A), the shear modulus $(\mu)$ and Burgers vector (b).

$$
\sigma_{\text {comp. }}=\mathrm{f}_{\mathrm{Cu}}\left[\sigma_{\mathrm{o}}+\frac{\mathrm{MA} \mu \mathrm{b}}{2 \pi \mathrm{t}} \ln \frac{\mathrm{t}}{\mathrm{b}}\right]_{\mathrm{Cu}}+\mathrm{f}_{\mathrm{Fe}}\left[\sigma_{\mathrm{o}}+\frac{\mathrm{MA \mu b}}{2 \pi \mathrm{t}} \ln \frac{\mathrm{t}}{\mathrm{b}}\right]_{\mathrm{Fe}}
$$

This equation is presented in Fig. 5, for comparison with the experimental data of the $\mathrm{Cu}-\mathrm{Fe}$ composites. It is seen that the fit of theory and experiment is reasonable at low strains, where fibres are not yet well formed, but deviates increasingly at high strains as the fibrous microstructure becomes established. A modified version of the above theory is proposed here (3), wich considers that the fibres are so strong (as a nanocrystalline phase of dimension $\mathrm{t} \approx 4-7 \mathrm{~nm}$ ) that they are loaded only elastically at the yield point of the composite:

$$
\sigma_{\text {comp. }}=\frac{f_{\mathrm{Cu}}\left(\sigma_{\mathrm{o}}(\mathrm{Cu})+\sigma_{\text {ribbons }}+\sigma_{\mathrm{part}}\right)+f_{\mathrm{Fe}} 0.2 \% \mathrm{E}_{\mathrm{Fe}}}{1-\frac{f_{\mathrm{Fe}} \mathrm{E}_{\mathrm{Fe}}}{\mathrm{E}_{\text {comp. }}}}
$$

This equation, presented in Fig. 6 for comparison with the experimental data, shows improved agreement with this data implying that the model developed is a correct description of the mechanical behaviour of the fibre-reinforced composite.

\section{CONCLUSIONS}

The present work using rapidly solidified powders of $\mathrm{Cu}-\mathrm{Fe}$ alloy shows that it is possible to achieve very fine microsturctures and very high strengths by moderate working of the initial refined microstructure. There is clearly a need to avoid impurity contamination of the alloys during fabrication such that the bcc metal phase deforms readily to fibre form. A modified version of the composite hardening model is used which takes account of the high strength of the nanodimensioned fibres, which thus are strained only elastically at the yield stage of the composite.

\section{REFERENCES}

1 J.D. Verhoeven, H.L. Downing, L.S. Chumbley and E.D. Gibson, J.Appl. Phys., 65, 1293 (1989).

2. J.D. Verhoeven, S.C. Chueh and E.D. Gibson, J. Mater. Sci., 24, 1748 (1989).

3. C. Biselli and D.G. Morris, Acta Metall. et Mater., in press.

4. P.D. Funkenbusch and T.H. Courtney, Scripta Metall., 15, 1349 (1981).

5. J.D. Verhoeven, L.S. Chumbley, F.C. Laabs and W.A. Spitzig, Acta Metall., 39, 2825 (1991).

6. W.A. Spitzig, J.D. Verhoeven, C.L. Trybus and L.S. Chumbley, Scripta Metall., 24, 1171 and 1181 (1990). 


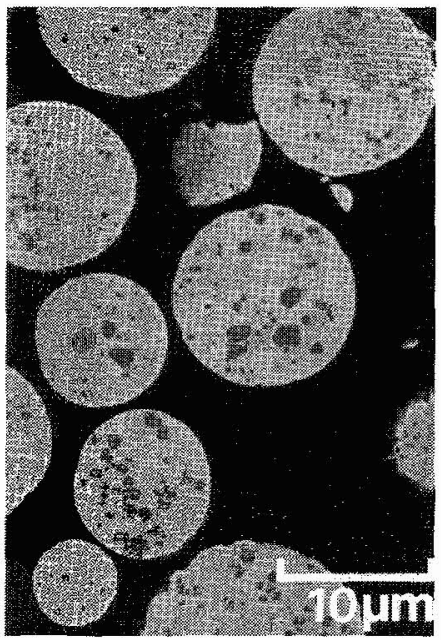

Fig.1: Fe particles inside a $\mathrm{Cu}$ $-15 \% \mathrm{Fe}$ alloy powder

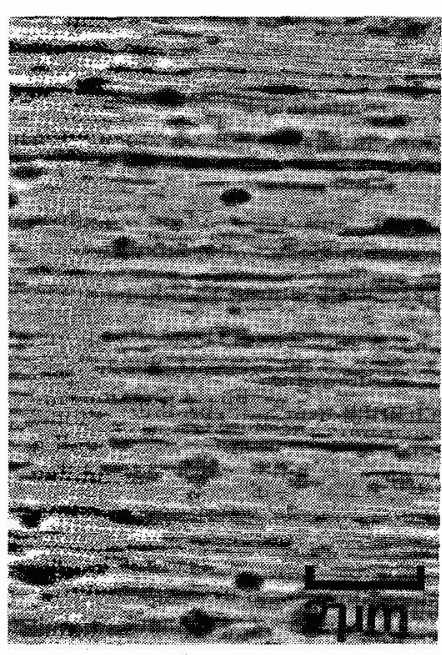

Fig.2: Elongated Fe parricles after drawing to $\eta=6.2$

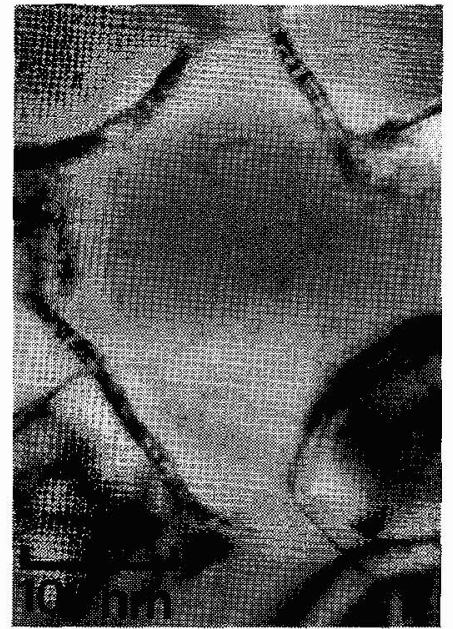

Fig.3: Fe fibres in $\mathrm{Cu}-\mathrm{Fe}$ after drawing to $\eta=6$

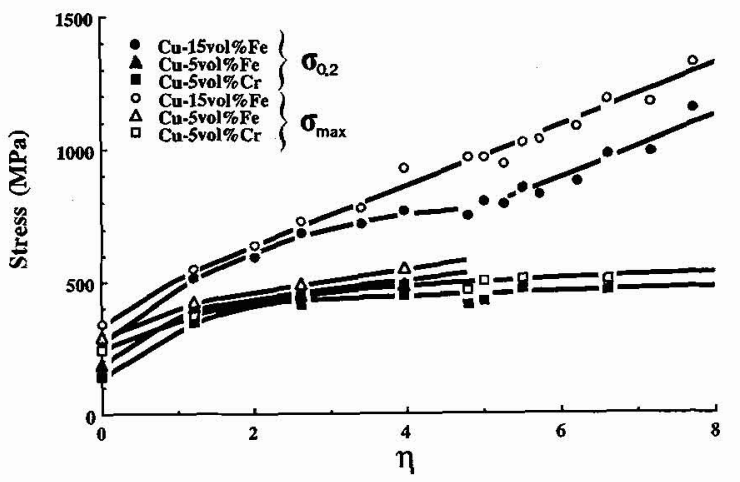

Fig.4: Results of tensile tests on several $\mathrm{Cu}$-bcc metal alloys after drawing to the strains indicated

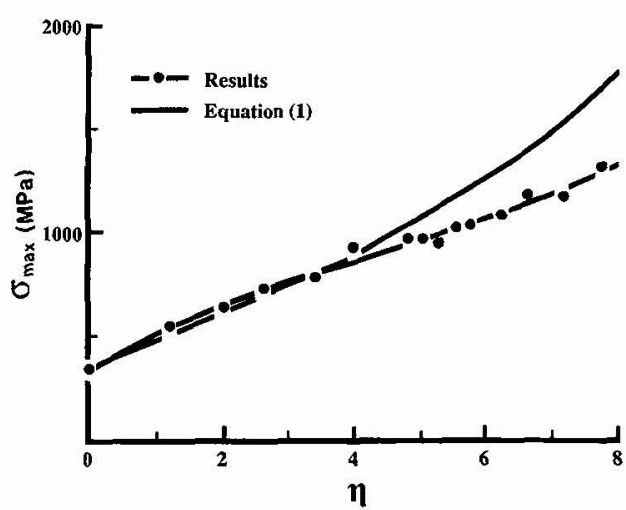

Fig.5: Comparison between theory (equation 1) and experimental tensile data on $\mathrm{Cu}-15 \mathrm{Fe}$

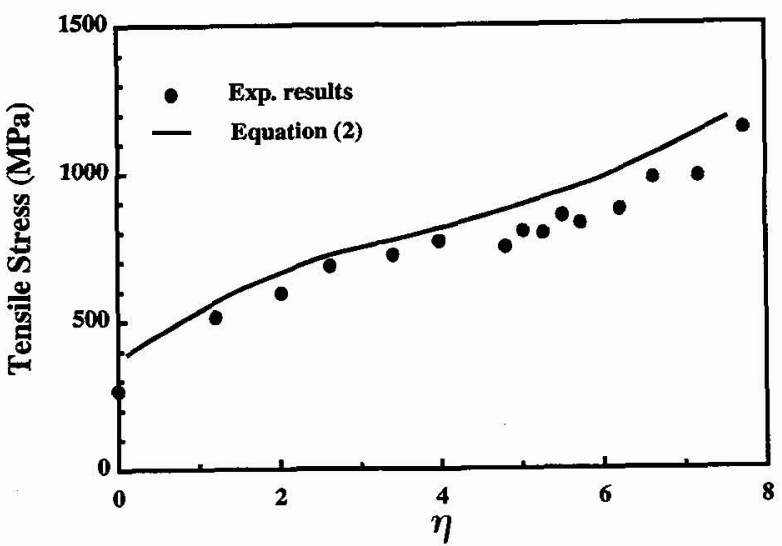

Fig.6: Comparison between theory (equation 2) and experimental tensile data on $\mathrm{Cu}-15 \mathrm{Fe}$ 